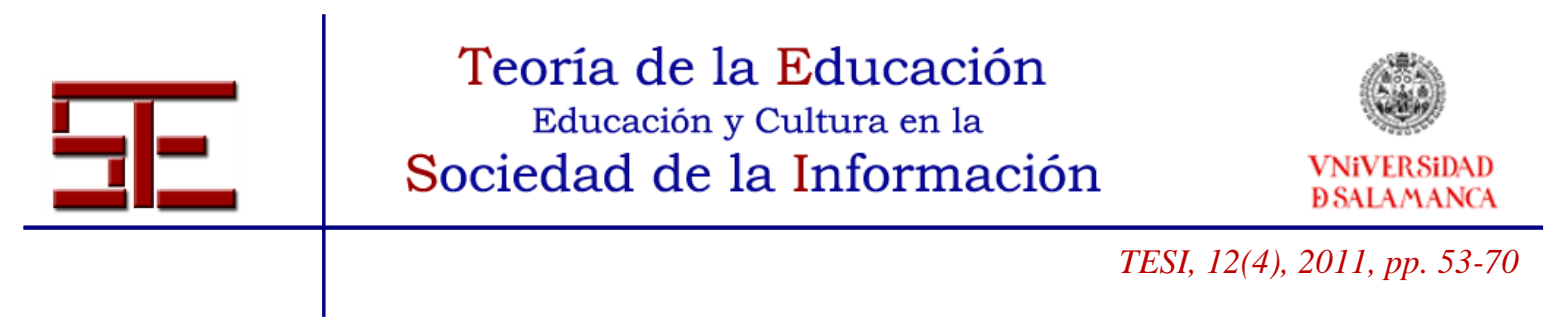

\title{
CREACIÓN DE UN BLOG EDUCATIVO COMO HERRAMIENTA TIC E INSTRUMENTO TAC EN EL ÁMBITO UNIVERSITARIO
}

Resumen: El Espacio Europeo de Educación Superior (EEES) ha posibilitado en gran medida la incorporación de las Tecnologías de la Información y la Comunicación (TIC) en las aulas universitarias. Sin embargo, el tema que actualmente está siendo debatido es si realmente las TIC pueden llegar a considerarse como un instrumento tecnológico y educativo que permita el aprendizaje del conocimiento (TAC).

La experiencia que recoge este estudio se centra en la creación de un blog educativo en la asignatura de "TIC aplicadas a la Educación" en $1^{\circ}$ de Grado de Maestro en Educación Primaria en la Universidad de Burgos durante el curso 2010/2011. El trabajo realizado a partir del blog ha contribuido al aprendizaje co-constructivista no sólo de las TIC y a través de las TIC, sino también como una aplicación didáctica, en este caso de colaboración y trabajo cognitivo. Y a su vez, dentro del currículum oculto ha pretendido la concienciación, sensibilización y aproximación a la atención a la diversidad, como tema transversal y eje principal de contenidos.

Palabras clave: Alfabetización informacional; proceso de aprendizaje; Cognición y Tecnología Educacional.

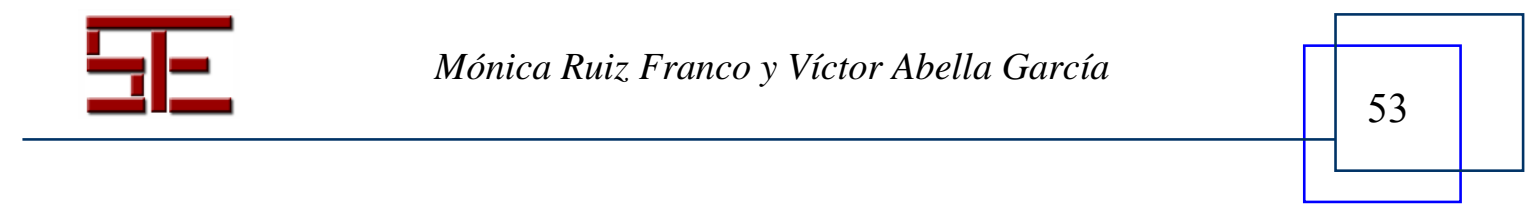




\title{
LAUNCHING A LEARNING BLOG AS TIC AND TAC TOOL IN THE SPHERE OF UNIVERSITY
}

\begin{abstract}
The European Higher Education Area has made possible the incorporation of Information and Communication Technologies (ICT) in University's classes. However, nowadays it is being hotly debated whether ICT can be considered as a technology and educative tool that allows learning about knowledge.
\end{abstract}

The creation of an educative blog in the subject of "ICT applied to Education", from the degree in Pre-primary Education of the University of Burgos (2010/2011) is the focus of this research. The conclusion that can be drawn from this experience is that the use of the blog has not only made possible a co-constructivist learning of knowledge of ICT through ICT, but also has contributed to collaborative and cognitive work being a learning tool itself. Besides, within occult curriculum, it has sought to raise awareness on attention to diversity as its guideline and key topic.

Keywords: Information literacy; learning processes; Cognition and Educational technology.

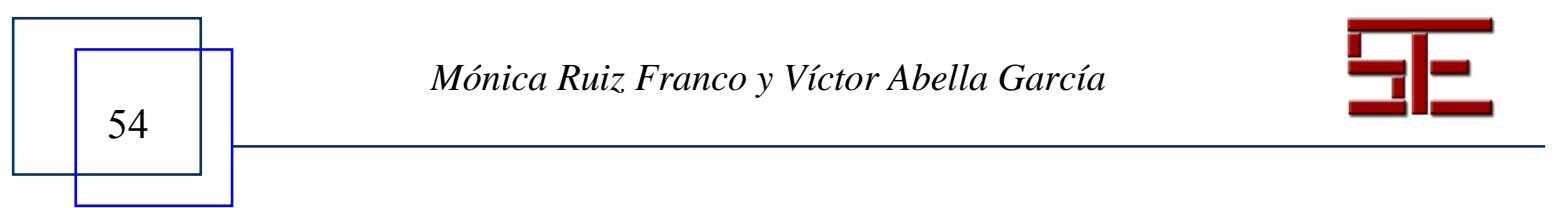




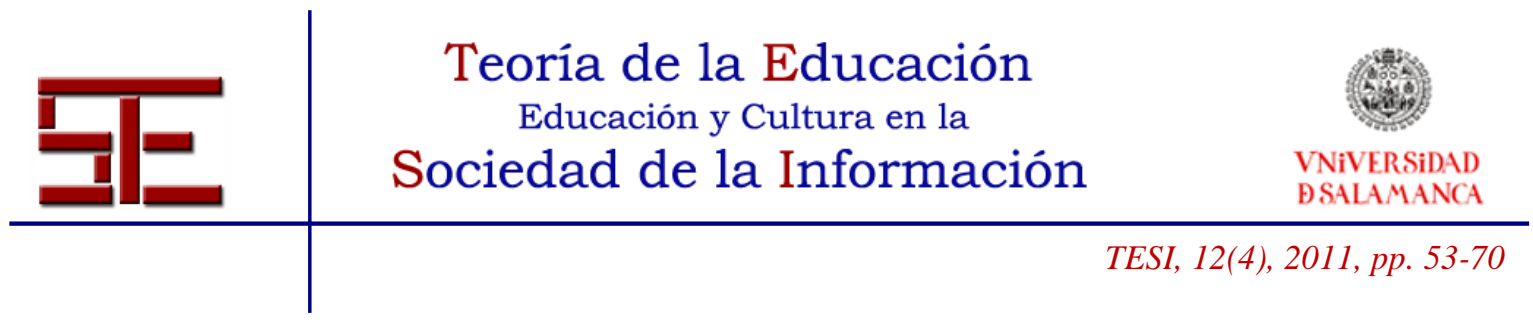

\section{CREACIÓN DE UN BLOG EDUCATIVO COMO HERRAMIENTA TIC E INSTRUMENTO TAC EN EL ÁMBITO UNIVERSITARIO}

Fecha de recepción: 31/10/2011; fecha de aceptación: 01/012/2011; fecha de publicación: 20/12/2011

\section{Mónica Ruiz Franco \\ mrfranco@ubu.es \\ Universidad de Burgos \\ Víctor Abella García \\ vabella@ubu.es \\ Universidad de Burgos}

\section{1.- INTRODUCCIÓN}

El actual escenario europeo de educación superior lleva en los últimos años emprendiendo diversas acciones de transformación educativa que responden a las demandas y necesidades de la sociedad actual. Entre ellas, cabe señalar la integración y uso de las TIC en los modelos de enseñanza y aprendizaje, la formación permanente, los avances científicos y tecnológicos (Rodríguez Izquierdo, 2010) y la importancia de la calidad de la enseñanza para el futuro profesional y personal del estudiante.

Entre las citadas reformas educativas que caracterizan el EEES, resulta imprescindible mencionar uno de los ejes que guían la actual educación universitaria como es la formación en "competencias clave", que estableció en 2006 la Comisión Europea (2007) para el aprendizaje permanente. Las ocho competencias que componen dicho marco de referencia (entre ellas, la competencia digital) se orientan a la realización personal, profesional y social de las personas como ciudadanos activos en muy diversos contextos.

Entre las transformaciones que ha experimentado este nuevo escenario universitario haremos referencia al papel de las tecnologías de la información y la comunicación y concretamente a la Web 2.0 y su aplicación en la educación.

Ferding (2006) y Maloney (2007) señalan que a pesar de que las herramientas de la Web 2.0 no fueron diseñadas con fines educativos, actualmente conforman un recurso esencial para abordar los nuevos desafíos en los procesos de enseñanza-aprendizaje.

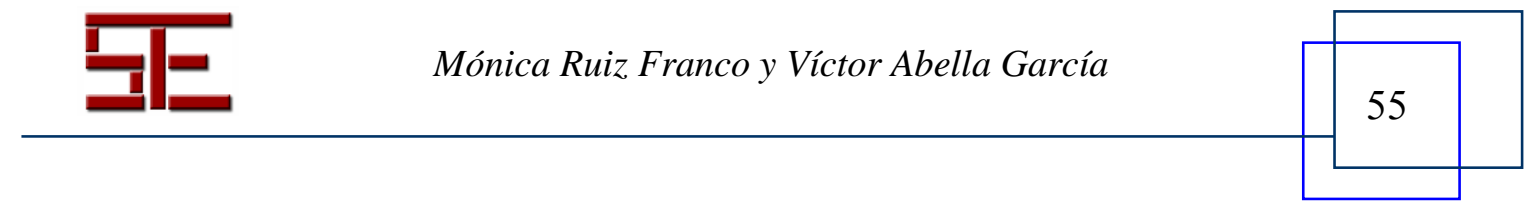




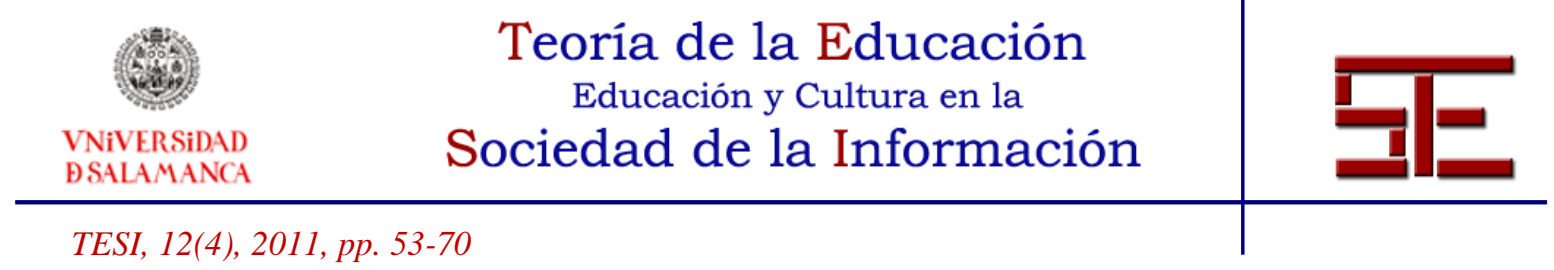

Repasando las principales características de la Web 2.0 señalaremos su fácil acceso, el papel activo que los usuarios tienen al poder controlar los datos e información, la constante actualización de contenidos (Maloney, 2007) y las posibilidades para crear, modificar y compartir contenidos con los demás (Alexander, 2006).

En este sentido, y parafraseando a Echazarreta, Prados, Poch y Soler (2009) podemos observar como el Plan Bolonia entiende el aprendizaje desde la responsabilidad del alumnado, que pasa a convertirse en un sujeto activo en la construcción de su propio aprendizaje. No sólo es un enfoque centrado en el estudiante, se trata de que ahora el alumnado controla, gestiona, ordena... su aprendizaje.

Continuando con las características de la Web 2.0, indicamos como el paso del "estaticismo", es decir, de las páginas web que eran únicamente de lectura y se desarrollaban en entornos planos de observación unidireccional (Web 1.0) a la combinación de lectura y escritura con una gran fluidez de información ha permitido la interacción y colaboración entre los usuarios, y la elaboración y construcción de un nuevo conocimiento (De Haro, 2010a). De este modo, podemos señalar que la Web 2.0 permite al usuario ser lector y escritor de contenidos con un papel activo (López Meneses, 2009) en entornos de comunicación e interacción bidireccional y multidireccional (Lozano, 2008).

Dentro de este cambio de mentalidad y de actitud que envuelve a la Web 2.0, encontramos diversas aplicaciones que posibilitan al estudiante colaborar e interactuar activamente con otros compañeros/as, publicar y ser co-protagonistas de su aprendizaje. Algunas de estas aplicaciones pueden ser los blogs, wikis, redes sociales, sindicaciones, marcadores sociales, folksonomías, podcast, etc.

Podemos concluir diciendo que el principio pedagógico que guía la Web 2.0 es el llamado constructivismo social (Ferdig, 2007). Este modelo utiliza las TIC como herramientas para el aprendizaje significativo a través de la combinación de experiencias, las conexiones con el mundo real, la retroalimentación, la interacción entre el profesorado y alumnado, la ubicuidad, la posibilidad de compartir, colaborar y elaborar, y por último por el papel activo, el compromiso y la independencia que se otorga al alumnado (Hernández Requena, 2008).

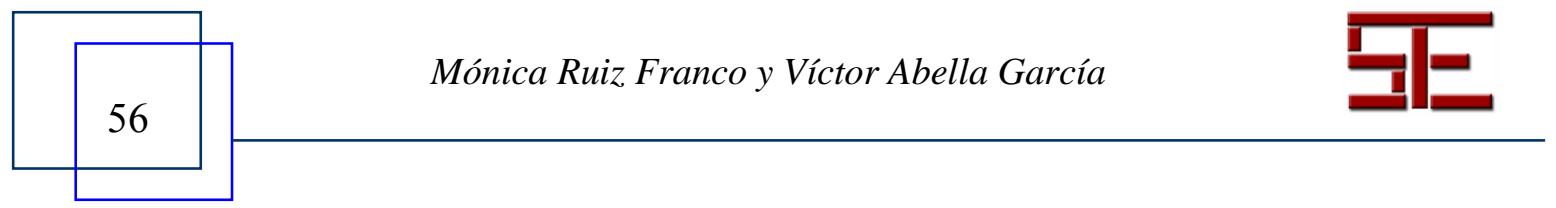




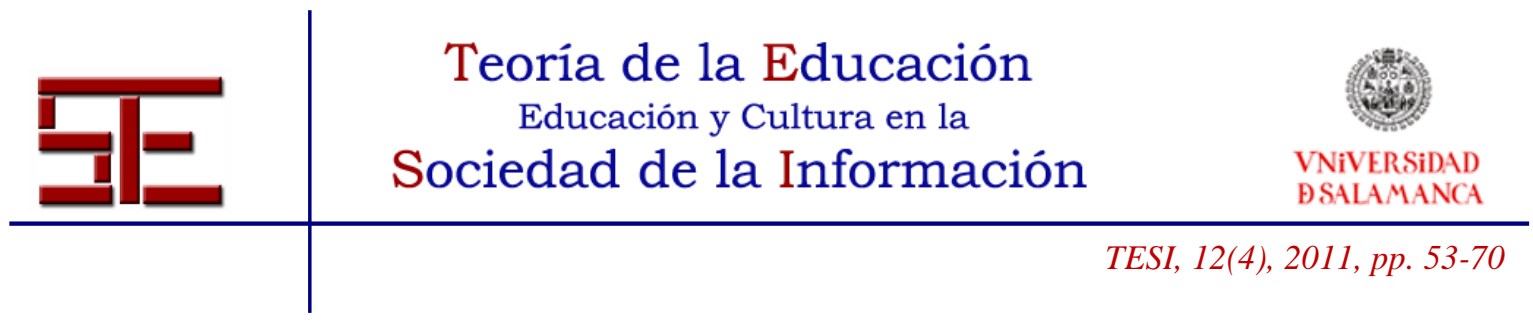

\section{2.- EL BLOG EDUCATIVO: UNA TIC CONVERTIDA EN TAC}

Dentro del proceso de introducción de las TIC en el nuevo paradigma educativo 2.0 comenzamos enseñando qué eran las TIC, después hemos pasado a enseñar a través de las TIC hasta el momento actual en el cual utilizamos las TIC como instrumento del proceso de enseñanza aprendizaje, es decir, como Tecnologías del Aprendizaje y el Conocimiento (TAC) (Espuny; Gisbert; González y Corduras, 2010).

En este sentido, Vivancos (2011a) afirma que "las TIC no son solo tecnología, son lo que podemos hacer con ella". Por tanto, las TAC no sólo hacen referencia a saber utilizar una herramienta o aplicación, sino que guían las TIC hacía marcos más educativos-formativos. Se trata de explorar el uso didáctico de las TIC para el proceso de enseñanza-aprendizaje (Lozano, 2011).

El proceso de TIC a TAC, tal y como indica Sancho Gil (2008), no es sólo un cambio de vocal, sino que conlleva la innovación pedagógica y la mejora del aprendizaje recogido en un contexto educativo con unos objetivos y un seguimiento. Esta autora defiende que la transformación de TIC a TAC será muy difícil sino se produce un cambio en la práctica docente, así como en su formación inicial y permanente y en el sistema organizativo de la enseñanza.

La cuestión es si el uso que damos a las TIC tiene una finalidad comunicativa, educativa, de retroalimentación...es decir, si se produce un aprendizaje o por el contrario son utilizadas como elemento motivador. Tal y como indica Rodríguez Izquierdo (2010) tendríamos que reflexionar cómo revolucionaron la educación y concretamente el aprendizaje la radio, la televisión, el vídeo... y si las TIC van a ser diferentes. Surge entonces la cuestión de cuál es el uso que damos a estas TIC (cuál dimos a las "antiguas"), y si en verdad contribuyen al aprendizaje o suponen en muchos casos una sobrecarga tanto para el docente como para el estudiante.

Ante este emergente paradigma, queremos mostrar a través de nuestra experiencia cómo la creación de blogs educativos, herramientas TIC, puede convertirse en un instrumento TAC enmarcado dentro de las aplicaciones de colaboración y trabajo cognitivo que señala Vivancos en su clasificación (2011b). Y además queremos dar a conocer cómo la creación del blog educativo ha supuesto un canal de aprendizaje, un medio y una herramienta de apoyo y no un fin en sí mismo.

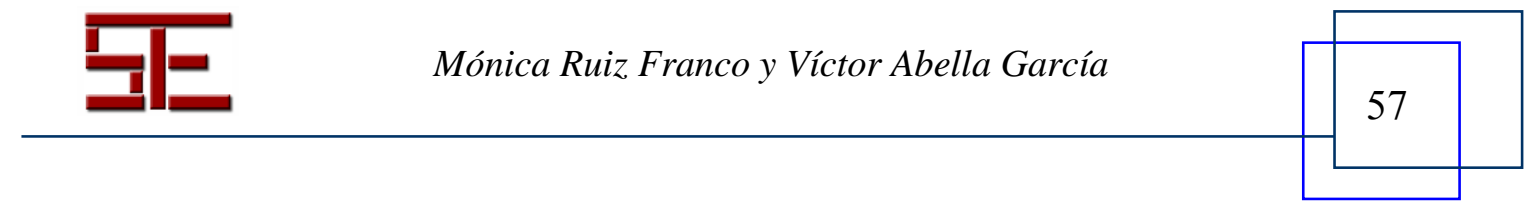




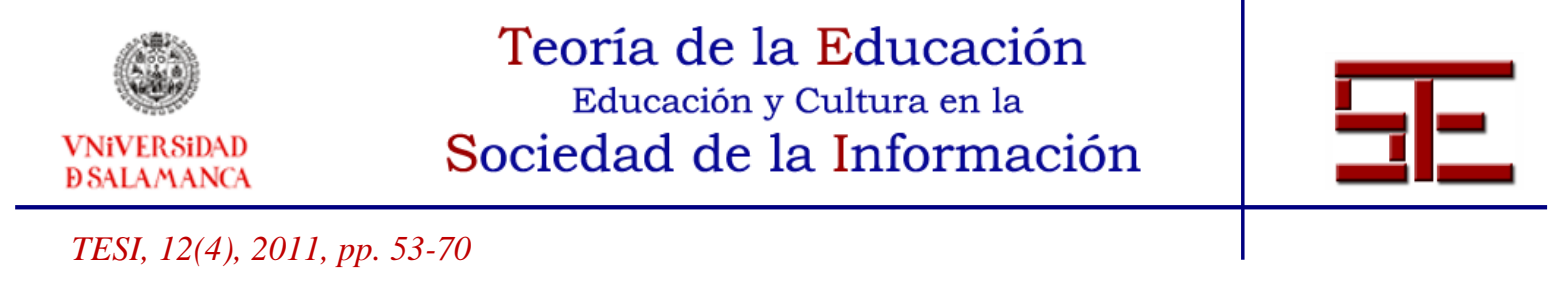

Desde nuestra perspectiva como docentes hemos pretendido posibilitar al alumnado un aprendizaje socio-co-constructivista y colaborativo, con contenidos informales, abiertos a toda la comunidad, basado en la interacción y con la principal tarea de que "aprendan a aprender". Nuestro papel ha sido de guías y facilitadores en el "empoderamiento" del aprendizaje por parte del alumnado. Y así, posibilitarles la creación o reformulación de andamiajes cognitivos cada vez más complejos que les permitieran llegar a su zona de desarrollo próximo.

Finalmente, debemos tener en cuenta como docentes un aspecto clave para la integración de las TIC como medio y como TAC, la formación e innovación permanente del profesorado que resulta imprescindible en esta "cultura de convergencia" y que pretende la adquisición de nuevas competencias para su "realfabetización digital" (Gutiérrez Martín, 2009) y consecuentemente para su cambio metodológico.

\section{3.- CONTEXTUALIZACIÓN DE LA EXPERIENCIA}

Los blogs constituyen un "sistema de publicación de artículos, llamados también entradas o posts" ( De Haro, 2010a, 167). Son un medio de comunicación colectivo que permite la creación y consumo de información original y veraz, posibilitando la reflexión individual y social (Contreras, 2004). El servicio Blogger lo define como una "tribuna de orador".

Existen diferentes tipos de blogs, pero en este caso sólo nos centraremos en el educativo o edublog, cuyo objetivo es la gestión de proyectos colectivos entre diversos estudiantes (De Haro, 2010b).

La construcción de un edublog se desarrolló en la asignatura de "Tecnologías de la Información y la Comunicación aplicadas a la Educación" en el primer curso de grado de Maestro en Educación Primaria de la Universidad de Burgos en el primer semestre del curso 2010/2011.

Con un total de 173 alumnos (36,4\%) y alumnas (63,3\%) matriculados, las clases se dividen en tres grupos de alrededor de 60 estudiantes por aula. El 67,5\% de la muestra (datos obtenidos de una encuesta realizada en enero de 2011 al alumnado, total de respuestas: 157) tiene una edad comprendida entre los 18 y 19 años, y tan sólo un 5,1\%

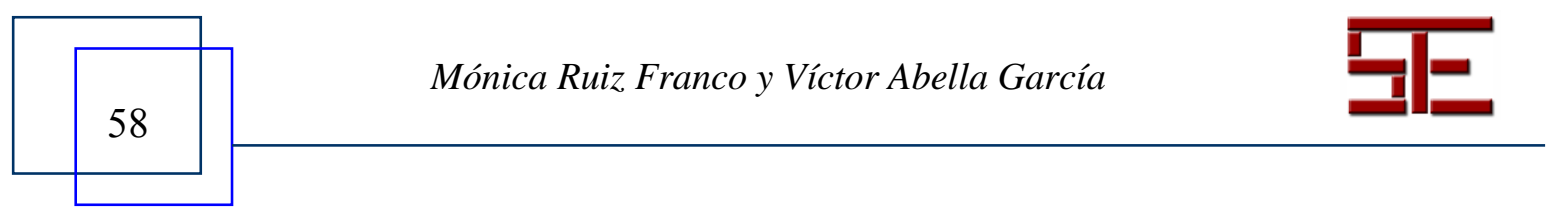




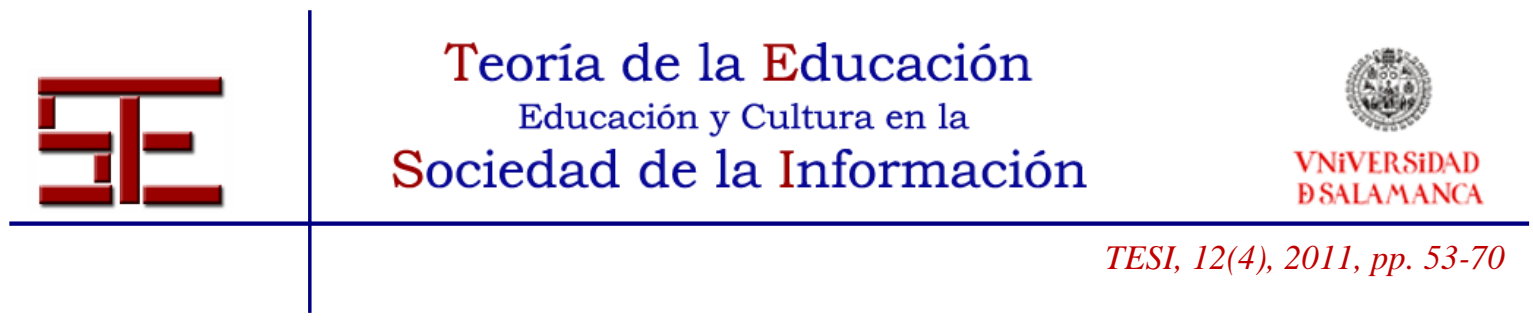

tiene más de 25 años. El 23\% restante corresponde a la franja entre los 20 y los 25 años (el 4,4\% del alumnado no indica la edad).

Al inicio de la asignatura un $89 \%$ de los alumnos/as dijeron conocer lo que era un blog, mientras que el $11 \%$ restante reconoció que desconocía esta herramienta. Aquellos que dijeron conocer la herramienta se les preguntó acerca de su dominio de la misma (Figura 1). Podemos observar como un 53\% del alumnado reconoció tener un dominio bajo o muy bajo, mientras que un $22 \%$ afirmó tener un dominio medio. Un dominio alto del manejo del blog sólo fue escogido por el 17\% y tan sólo un $8 \%$ indicó que tenía un dominio muy alto.

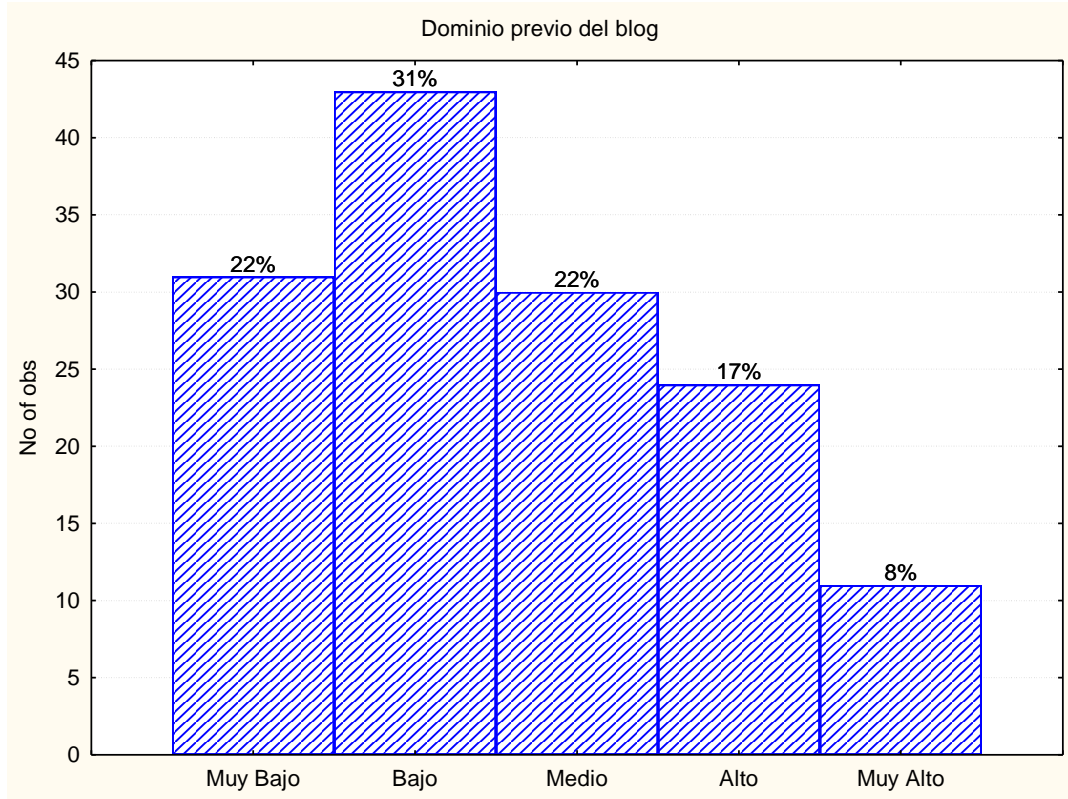

Figura 1. Grado de dominio de la herramienta blog al inicio de la asignatura.

Los contenidos que trata esta asignatura están centrados en las diferentes aplicaciones y herramientas de la Web 2.0. La parte práctica (creación de un blog, wiki, actividades en JClic, trabajos de iniciación a la investigación de la Web 2.0, exposiciones, defensas...) supone el $60 \%$ de la nota global, mientras que el resto corresponde a la evaluación escrita y a las tutorías. Tanto los documentos teóricos, como las actividades, recursos, enlaces, etc., que se trabajan en el aula se registran en la plataforma UBU-Virtual basada en un software de gestión del aprendizaje, Moodle, al que todos nuestros estudiantes tienen acceso.

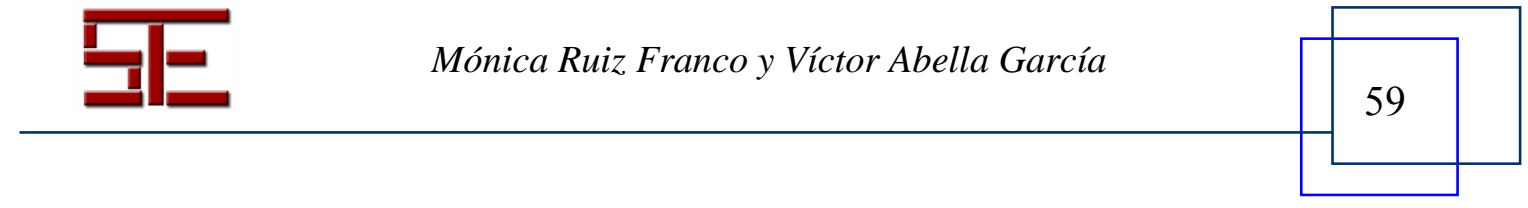




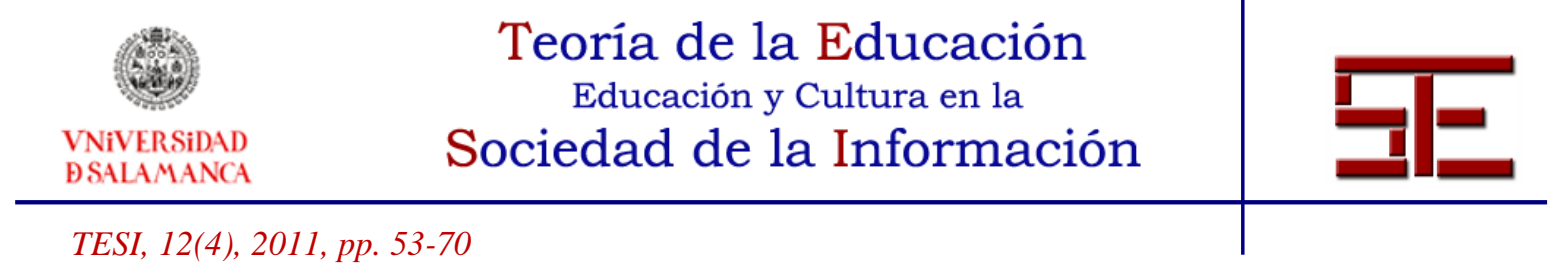

\section{4.- ¿POR QUÉ UTILIZAMOS UN BLOG?}

El blog educativo fue una de las actividades prácticas que utilizamos como recurso didáctico innovador ya que, al igual que los principios que sustentan el EEES, esta herramienta promueve la construcción de aprendizajes que se centran en las competencias básicas y en temas transversales (Ariel, 2005). En esta línea pretendimos que los estudiantes adquirieran, por un lado, las destrezas y competencias necesarias para desenvolverse con este tipo de herramientas de comunicación (competencia digital), contribuyendo de esta manera a su formación (competencia de aprender a aprender) como parte de su Entorno Personal de Aprendizaje (PLE).Y, por otro lado, a la adquisición de conocimientos, sensibilización y concienciación mediante una primera aproximación a la educación especial, la interculturalidad y el codesarrollo como temas transversales (competencia social y cívica).

Dado que nuestro punto de partida fue reflejar la realidad social a través de las TIC incluimos dentro de nuestro currículum oculto estos temas transversales potenciando el aprendizaje humano, de cooperación, los valores sociales, la justicia, la igualdad... y, por ende, un aprendizaje emocional.

Con esta actividad hemos pretendido que nuestro alumnado comprenda las TIC como un medio para la construcción del conocimiento, como un instrumento cognitivo, como un canal de comunicación y conexión con otras personas, como un medio de expresión y reflexión, como una fuente de información..., es decir, como una herramienta web bidireccional que permita la retroalimentación (Adell y Castañeda, 2010). Consecuentemente como parte de su Entorno Personal de Aprendizaje (PLE) el blog va a permitir el desarrollo de tres procesos cognitivos básicos, como son leer, reflexionar y compartir (Atwell, 2008). Dentro de los tres tipos de elementos que conformarían un PLE básico, los blogs pertenecerían fundamentalmente a las herramientas y estrategias de reflexión, es decir, aquellas que permiten transformar la información (Adell y Castañeda, 2010).

Por último, cabe añadir que el blog ha contribuido a la formación de los estudiantes gracias al pequeño trabajo de investigación experimental que desarrollaron mediante la búsqueda de información sobre las temáticas transversales señaladas anteriormente. Como indica De Haro (2010a), el gran incremento de información que encontramos en la Red ha dado lugar a una "infoxicación" o "sobrecarga informativa" que dificultó en

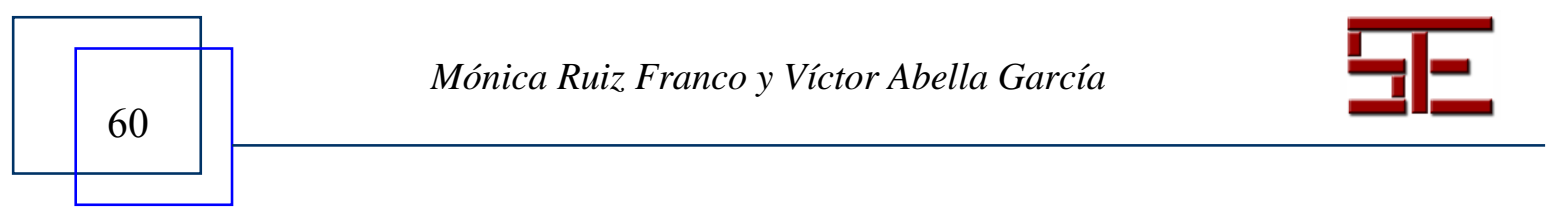




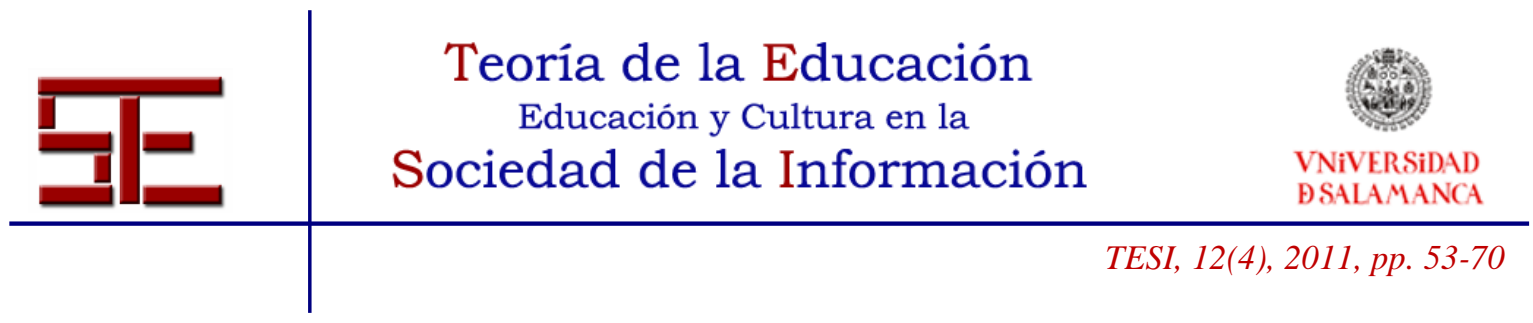

parte su aproximación a la investigación, pero por otro lado, les ayudó a discernir entre aquellos contenidos veraces, útiles, relevantes y significativos de los que no lo eran.

\section{5.- CONFIGURACIÓN DEL BLOG}

La creación del blog educativo de grupo se configuró a lo largo de 3 meses de duración, tiempo que los estudiantes dedicaron a trabajar en las horas de clases prácticas, tutorías dirigidas y de forma autónoma fuera del horario lectivo.

En la primera sesión realizamos una aproximación teórica al concepto de blog. Comenzamos explicando qué es un blog, cómo se clasifican (De Haro, 2010b), cuáles son sus características, el impacto que han tenido en la sociedad y cómo se han adaptado a la educación..., y a su vez les mostramos diversos ejemplos de blogs, desde los personales hasta los edublogs.

Desde comienzo de curso, para trabajar en grupos dividimos cada una de las tres clases en 12 pequeños grupos de 4-5 personas. De igual forma, establecimos 12 temáticas relacionadas con la atención a la diversidad, que constituyeron el eje de contenidos a tratar en diferentes trabajos que se llevaron a cabo durante el semestre (blog, wiki y Jclic).

Cada uno de los temas se repartió a los subgrupos mediante sorteo. Las diferentes temáticas fueron las siguientes: coeducación, interculturalidad, trastornos del lenguaje escrito y oral, asperger, síndrome de down, autismo, TDAH, altas capacidades, deficiencia visual y auditiva y, por último, discapacidad motora.

Comenzamos registrando cada uno de los blogs en el servicio gratuito de Blogger. Es necesario contar con una cuenta de correo electrónico de GMail, pero en nuestro caso la primera tarea que realizamos al inicio del curso fue que el alumnado se creara una cuenta ya que continuamente se trabajó con aplicaciones como Google Docs, Calendar y Picasa.

Una vez registrados los grupos y elegida la dirección web de su blog, donde constaba el nombre del mismo, fuimos explicando algunas de las funciones básicas que debían tener en cuenta para su configuración, diseño y desarrollo: estructura y elementos de la página, plantillas, cómo invitar a otros usuarios para ser editores; cómo se crean, modifican y eliminan las entradas; cómo comentar o votar una entrada; cómo se insertan

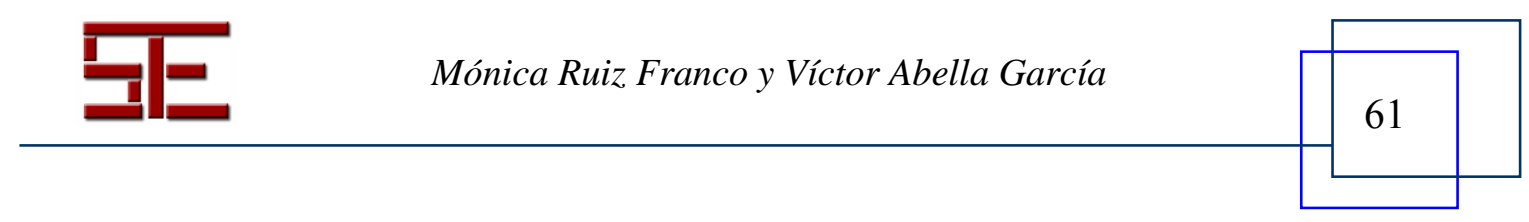




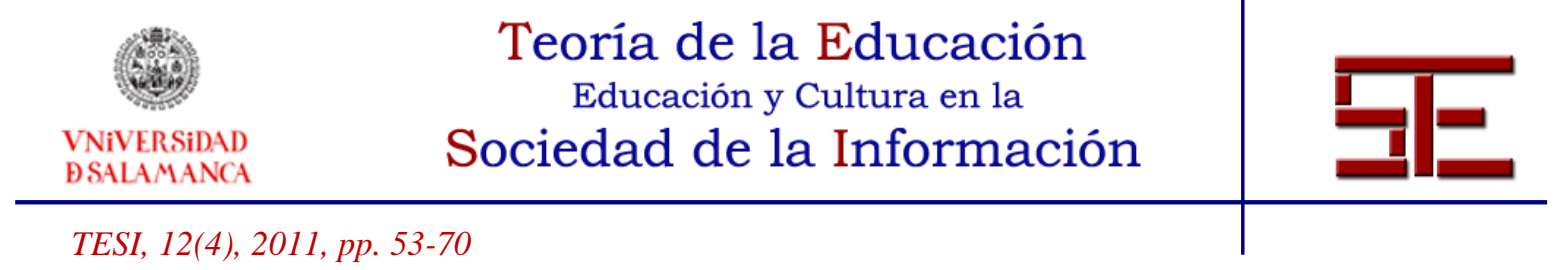

hipervínculos, fotos e imágenes; como incluir a través del embed vídeos, gadgets, presentaciones desde Google Docs o Slideshare...; el uso de HTML, etc.

Toda esta información quedó reflejada a través de tutoriales y videotutoriales que colgamos en la plataforma virtual, al igual que todas las direcciones de los blogs y las pautas para la realización de la actividad que presentamos a continuación.

Explicamos al alumnado cuál era su tarea, los requisitos mínimos que debían cumplir y una serie de orientaciones que les ayudaran a desarrollar su blog. Algunas de estas pautas fueron las siguientes:

a) Cada uno de los miembros del grupo debía realizar al menos tres entradas que incluyeran imágenes, texto, vídeos enlazados y con URL y que a su vez cada uno de estos post estuvieran etiquetados con las palabras clave que identificaran el contenido y con la autoría del mismo. Cabe señalar que la media de entradas por estudiante fue de 56 post, e incluso alguno de ellos llegó hasta 8 .

b) Debían evitar todo contenido formal (conceptualizaciones teóricas), basándose por el contrario en noticias relevantes y actuales, recursos educativos y tecnológicos, avances científicos, experiencias y testimonios, posibles soluciones, etc. Desde el primer momento se insistió en que ninguna de las entradas podían ser "copia y pega" y la importancia de referenciar o enlazar la fuente de los contenidos.

c) El blog tenía que contener una serie de gadgets mínimos como un chat, un reloj, un Ipod, un archivo de etiquetas y un contador de visitas. Este último dispositivo motivó enormemente al alumnado al comprobar como había muchas personas que visitaban su blog y se interesaban por su contenido. Prueba de ello, son las más de 5.000 visitas que diversos grupos recibieron durante la realización del blog. Un año después alguno de estos blogs ha superado las 10.000 visitas. Durante la creación del blog realizaron una importante difusión a través de redes sociales donde invitaban a conocerlo y a participar comentando sus entradas.

La gran mayoría de los grupos añadió otros gadgets como: traductores de idiomas, mascotas virtuales, el tiempo, frases célebres, sindicalizaciones, seguidores, enlaces a páginas web relacionadas con su temática, blogs (tanto de sus compañeros/as como externos al centro), el Twitter de la asignatura (\#edpr1011) y el suyo propio, enlace a la wiki del curso, banners con eslóganes (ej. "no escuchar, no debería ser motivo de

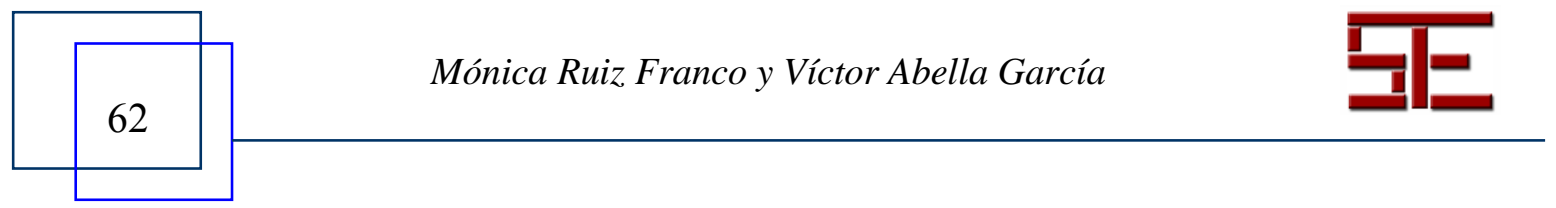




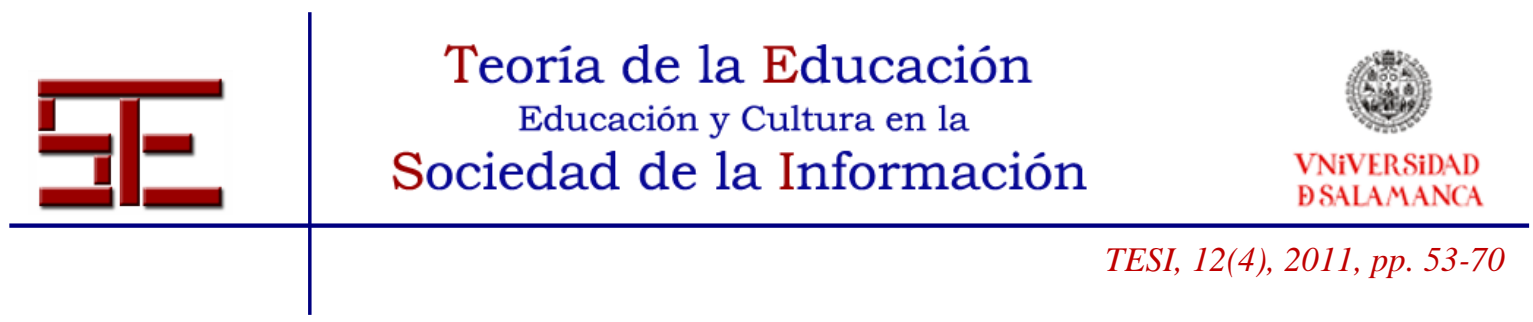

diferencia"), enlaces a otras redes sociales, noticias actuales, aplicaciones visuales que mejoraban la lectura de la información, encuestas, etc.

d) Para finalizar, uno de los aspectos más importantes del blog tanto para el profesorado como para los alumnos/as fue el apartado de comentarios. Entre las pautas establecidas, se indicaba que en diversas entradas los miembros del grupo debían comentar reflexivamente la información que alguno de sus compañeros/as había posteado. Su sorpresa fue cuando comenzaron a recibir comentarios de personas no vinculadas a la Universidad con mensajes de agradecimiento por su trabajo, de aliento y con preguntas sobre su temática que motivaron doblemente su estudio y análisis.

A su vez, dentro de cada una de las entradas introdujeron una aplicación, "reacciones", que permitía realizar una votación o comentario delimitado sobre la valoración del post (interesante, innovadora, educativa, divertido...).

Realizamos un seguimiento de cada uno de los blogs gracias a las sesiones prácticas realizadas en el aula y a las tutorías. Sin embargo, las horas de dedicación del trabajo práctico en el aula fueron disminuyendo a medida que fuimos incluyendo otras actividades. A pesar de las tutorías grupales, queríamos que el alumnado siguiera compartiendo sus avances y "descubrimientos" con el grupo-aula. Por esta razón, durante los últimos 15-20 minutos de las clases teóricas aquellos grupos que voluntariamente quisieran podían exponer al resto de sus compañeros/as cualquier información que consideraran importante por su contenido.

La actividad del blog finalizó con la exposición grupal de cada uno de los trabajos. Con un tiempo aproximado de 20 minutos por grupo debían explicar al resto de sus compañeros/as aquellas entradas más relevantes por su contenido social y educativo. Además hicieron un breve recorrido sobre el diseño y las aplicaciones que incorporaba el blog, los comentarios y visitas que habían recibido, los problemas que encontraron en la búsqueda de información, las diferencias que alberga su blog y que le hacían diferente al de los demás, etc.

\section{6.- CRITERIOS DE EVALUACIÓN}

Nos pareció imprescindible que nuestro alumnado contara de antemano con los criterios de evaluación que marcarían su calificación en la actividad del blog. Por esta razón

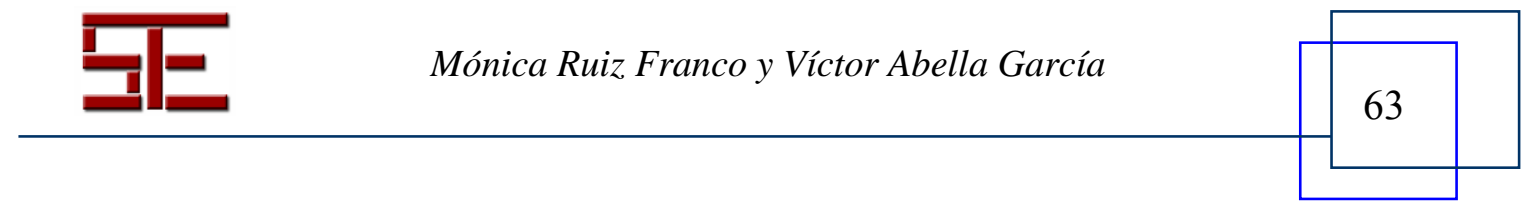




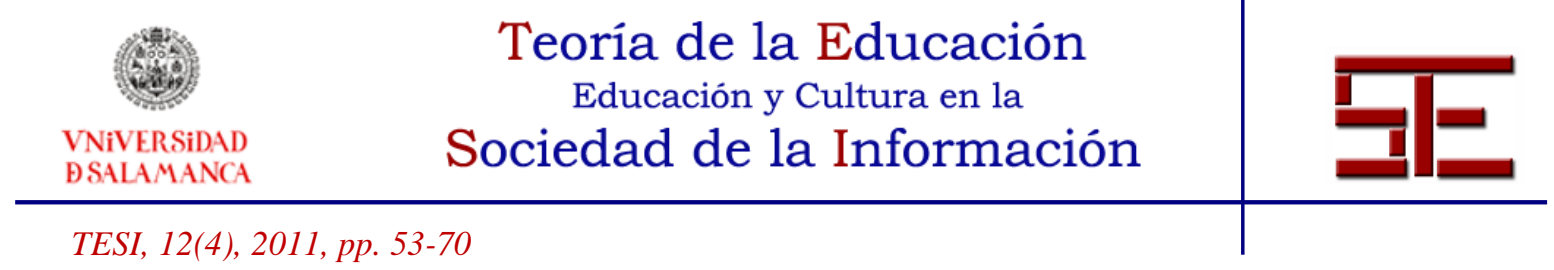

creamos un instrumento objetivo, una rúbrica, para que los estudiantes conocieran en todo momento de qué cuestiones iban a ser evaluados.

La rúbrica presentaba diversos contenidos a evaluar y el peso de cada uno de ellos. El $60 \%$ de la calificación correspondió al tratamiento de la información y a la calidad de los contenidos, y el $40 \%$ restante al diseño y estructuración del blog, su presentación, recursos utilizados, gadgets, comentarios, enlaces, uso de HTML, etc. Establecimos una serie de parámetros que medían dichos contenidos en insuficiente, regular, bien y excelente y éstos a su vez estaban divididos por una escala numérica. Por ejemplo: entradas multimedia (20\%), excelente entre 1,50 y 2,00 puntos (más de 8 entradas con vídeos, imágenes o audio con contenido preciso y adecuado al tema tratado).

A pesar de que la calificación final ha sido evaluada sólo por nosotros como docentes, nos pareció imprescindible que ellos mismos se autoevaluaran atendiendo a los criterios de la rúbrica para que fueran conscientes y realistas de aquellos contenidos que habían realizado correctamente, los que podrían mejorarse y también los que no habían incluido (influyó que pudieran comparar su trabajo con el de sus compañeros/as).

Pensamos que este sistema mejora su capacidad de reflexión y análisis, y por lo tanto su capacidad de aprendizaje. Y así lo demuestran las auto-calificaciones de las rúbricas que realizaron los grupos de trabajo, ya que se ajustan a lo que nosotros como docentes concluimos.

\section{7.- ALGUNOS EJEMPLOS DE BLOGS}

A continuación presentamos algunos de los blogs que realizó nuestro alumnado y que cuentan con la mayoría de las pautas que establecimos. Así podemos destacar "Música para mis oídos" (http://powerprimariab.blogspot.com/), por su estructuración y diseño, la sensibilización y recursos de sus entradas y por los banners de apoyo (cuenta actualmente con más de 10.800 visitas). Otro de los blogs sería "Diversidad Cultural" (http://pribg2.blogspot.com/), por la denuncia social que realizan a través de sus entradas, el estudio de la infancia y la educación y por los recursos audiovisuales que incluyen.

Por último, el blog "Soy ciego, pero capaz" (http://concuatrosentidos.blogspot.com/), ya que siguen manteniendo actualizado su blog, por las experiencias de personas afectadas que refleja, los recursos y aplicaciones tecnológicas que aporta y por la profundización y calidad de sus contenidos.

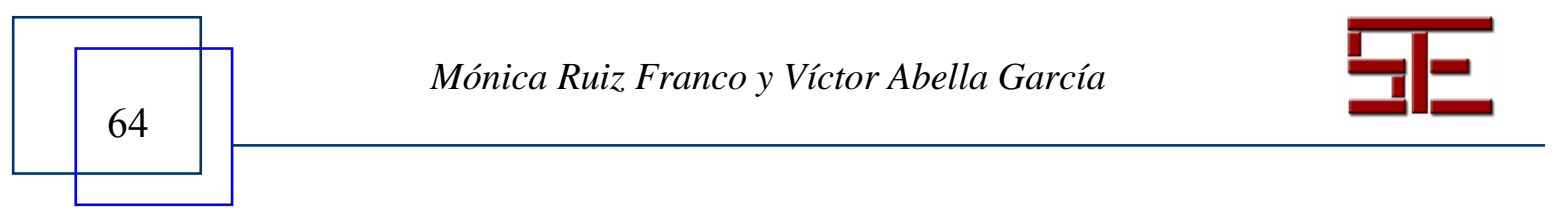




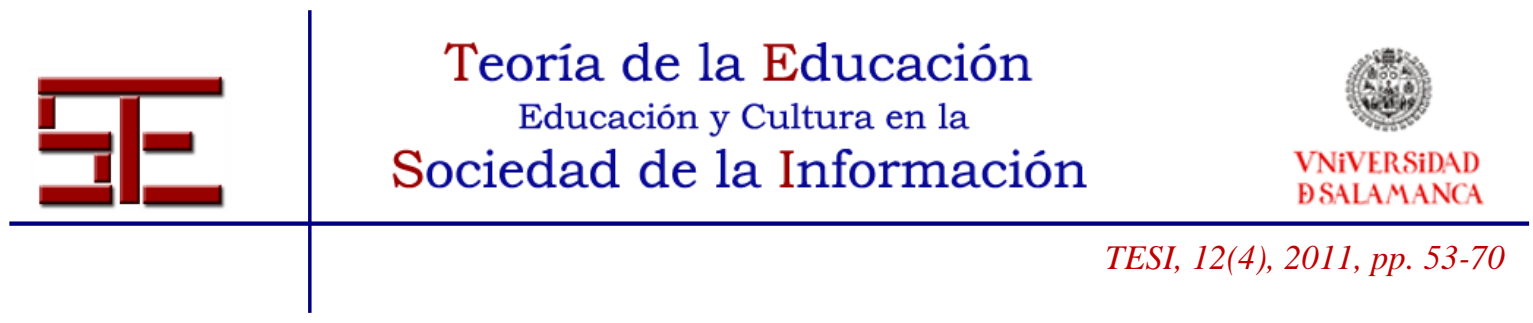

\section{8.- CONCLUSIONES}

Tras haber impartido la asignatura el $86 \%$ del alumnado considera que su nivel de dominio del blog (Figura 2) ha pasado a ser alto (61\%) e incluso muy alto (25\%). Por su parte, un $12 \%$ considera su nivel de dominio como medio y únicamente un $2 \%$ considera que su nivel sigue siendo bajo o muy bajo. Estos resultados nos indican que los alumnos/as han adquirido las habilidades necesarias para desarrollar un blog y prueba de ello es la media de las calificaciones obtenidas en este trabajo, 7,6, con un $2,3 \%$ de suspensos.

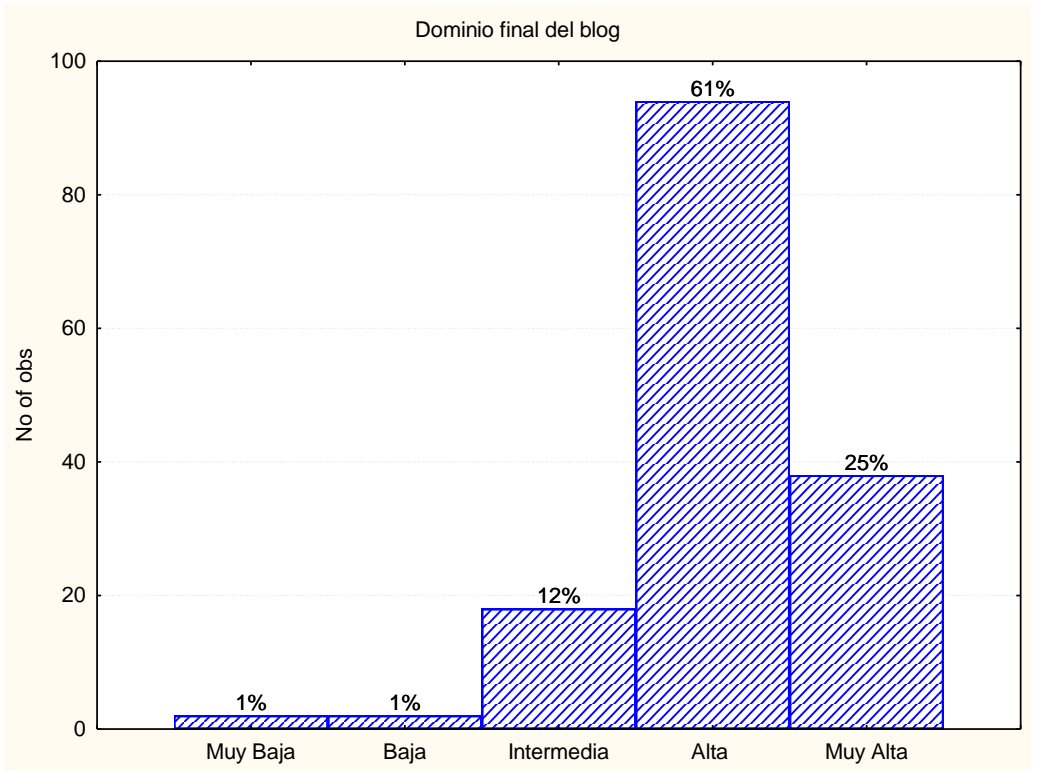

Figura 2. Grado de dominio de la herramienta blog al finalizar la asignatura.

Sin embargo, a pesar de que estas nuevas generaciones de "residentes digitales" se caracterizan, a priori, por su habilidad y aptitud para las nuevas tecnologías, desde nuestro punto de vista, dista, al menos en parte, la teoría de nuestra realidad en el aula. Exceptuando algunos casos, hemos percibido que si les sacamos de su contexto digital más próximo (Facebook, Tuenty, Youtube, descargas de música o vídeo, etc.) parecen entrar en un estado de inseguridad ante lo desconocido. Son inconscientemente competentes, tienen las destrezas y habilidades básicas necesarias, pero les cuesta ver en un primer momento que pueden lograrlo por sí mismos.

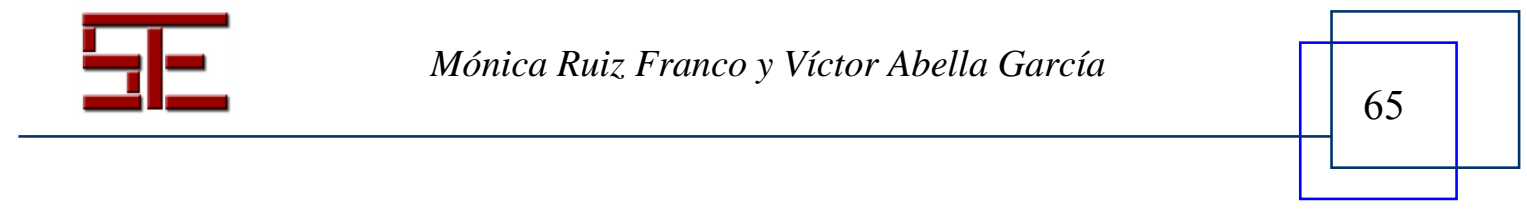




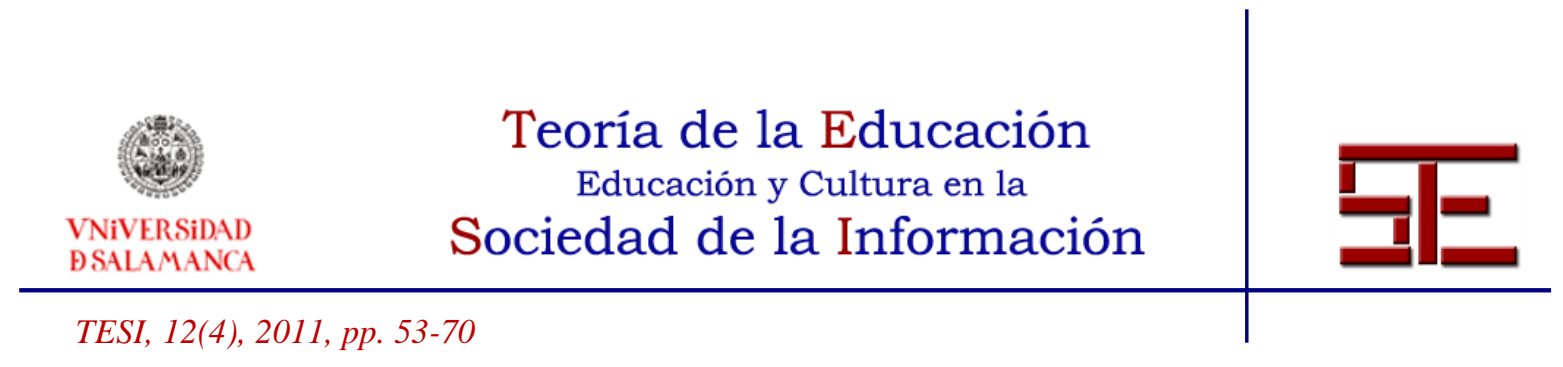

También se les preguntó sobre la utilidad educativa que para ellos tenían los blogs. Tal y como se puede ver en la Figura 3, un $81 \%$ del alumnado manifestó que la utilidad educativa de los blogs era elevada o muy elevada. Contrariamente, un 3\% de los alumnos/as consideraron que la utilidad educativa de los blogs es baja o muy baja. El $15 \%$ restante indicó que veía una utilidad media de los blogs en el ámbito educativo. En esta misma línea, un $94 \%$ de los estudiantes creían que utilizarían esta herramienta en su futuro educativo y profesional.

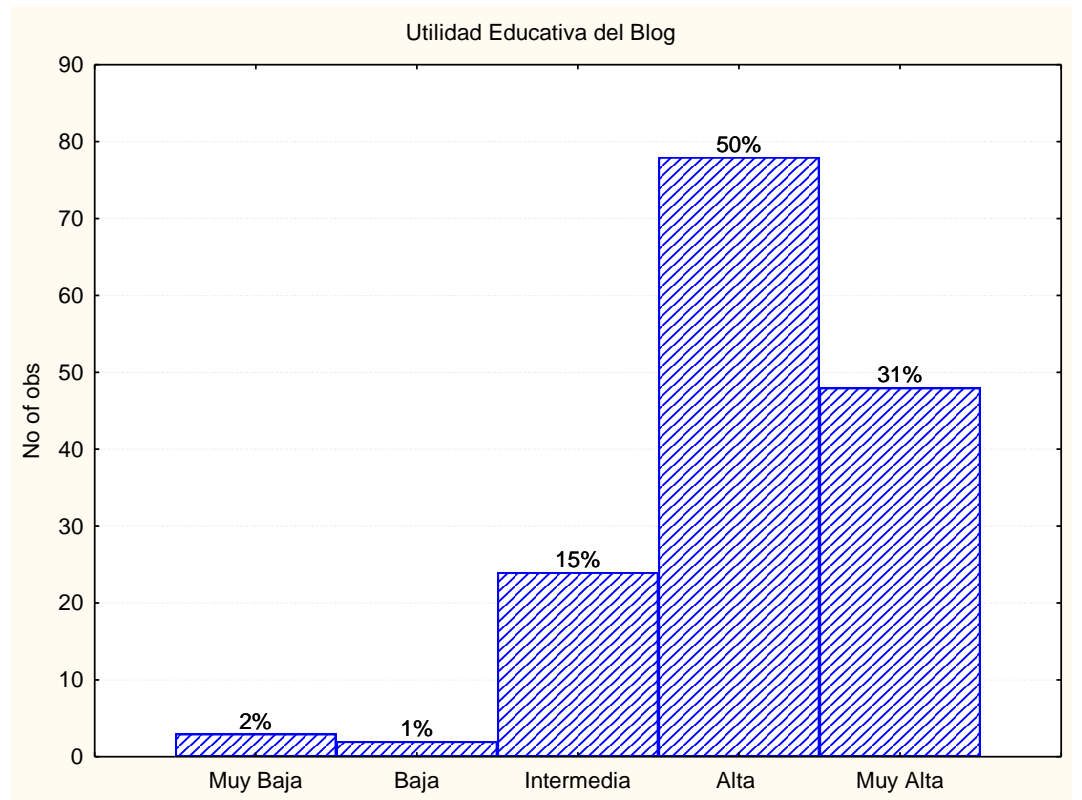

Figura 3. Valoración de los estudiantes sobre la utilidad educativa de los blogs.

Para finalizar queremos reflejar algunas de las limitaciones que hemos ido encontrando en este trabajo, como, por ejemplo:

1. Desde cada uno de los blogs podemos conocer qué y cuántas entradas ha realizado cada uno de los estudiantes, pero no quién ha configurado su estructura y diseño; y además, en algunos casos, no todos los miembros del grupo trabajan por igual (un miembro del grupo puede tener 3 entradas frente a otro que tiene 7 con contenidos de calidad). Nuestra solución en el presente curso escolar 2011/2012 ha sido realizar una

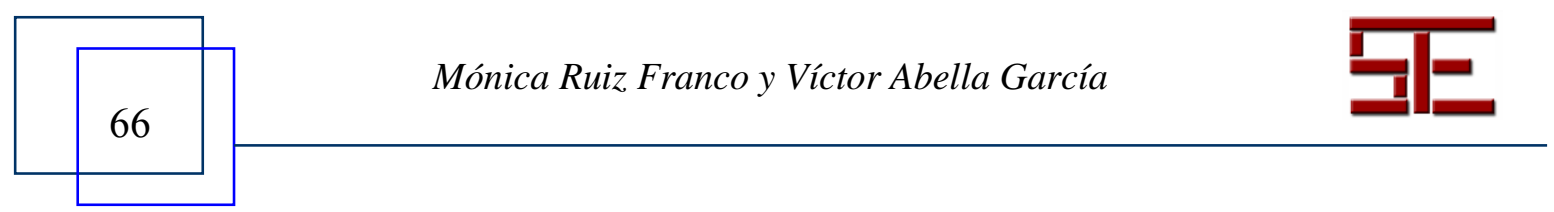




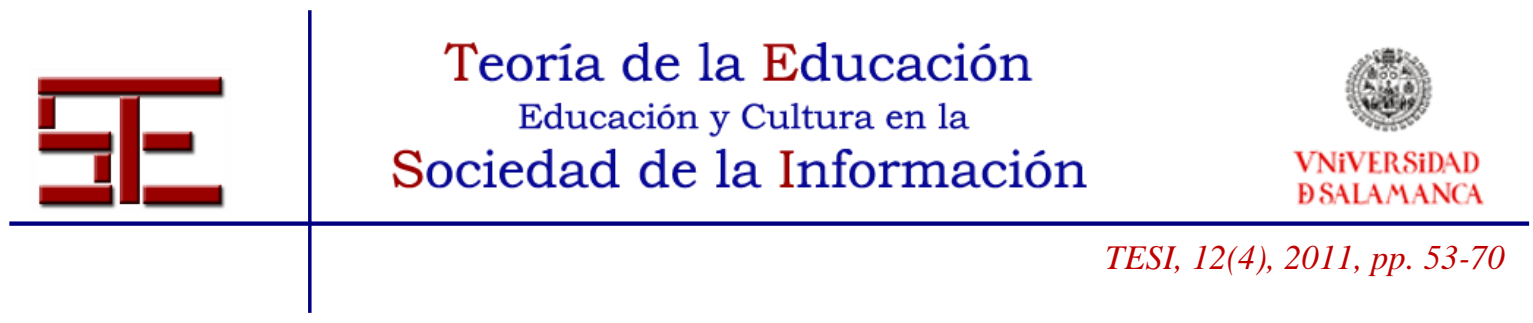

evaluación entre iguales donde se señalen los contenidos trabajados de cada uno y el grado de satisfacción por el trabajo de sus compañeros/as de grupo.

2. Sería interesante conocer cuántas visitas recibe el blog, eliminando las de los propios creadores. Una posible solución sería utilizar Google Analytics.

3. Por otro lado, en cuanto a la adquisición de conocimientos de los temas transversales que trabajamos, no podemos conocer a través de datos su nivel, ya que no eran temas de examen. Sin embargo, nos atrevemos a afirmar que han alcanzado los conocimientos mínimos (desde el punto de vista informal y de la realidad más latente que encontramos en la sociedad) en los temas transversales (discapacidad y trastornos, interculturalidad y codesarrollo) a través del aprendizaje constructivo y colaborativo, y que prueba de ello se refleja en las entradas del blog, las reflexiones, los comentarios, las defensas y las exposiciones de su trabajo. Nos quedamos con el proceso, antes que con el producto.

Para obtener algún dato más fiable del grado de conocimientos alcanzados sería posible realizar encuestas o documentos de reflexión. Sin embargo, y a pesar de que el alumnado visita y comenta los blogs de otros compañeros/as, no profundiza en el resto de temáticas, sino que sólo puede trabajarlos mínimamente.

4. Otra de las cuestiones que plantearon algún tipo de problema fue que en un primer momento la gran mayoría de los grupos no entendía muy bien a qué nos referíamos con contenidos informales. Sus primeras entradas se basaron en conceptualizaciones teóricas (qué es, características, tipos o clases...), pero poco a poco y, a través de la búsqueda y la indagación, encontraron contenidos más aproximados a la realidad.

De igual forma, hemos observado como en algunas de las temáticas, como por ejemplo en los trastornos del lenguaje oral y escrito, la búsqueda de contenidos informales ha resultado más complicada.

\section{BIBLIOGRAFÍA}

Adell, J. y Castañeda, L.J. (2010). Los Entornos Personales de Aprendizaje (PLEs): una nueva manera de entender el aprendizaje. En R. I. Roig Vila y M. Fiorucci (coords.), Claves para la investigación en innovación y calidad educativas, la integración de las tecnologías de la información y la comunicación y la interculturalidad en las aulas (pp. 19-33). Alcoy: Marfil.

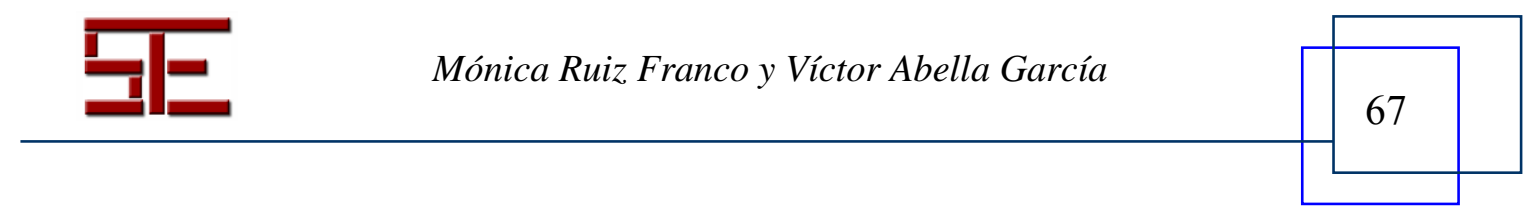




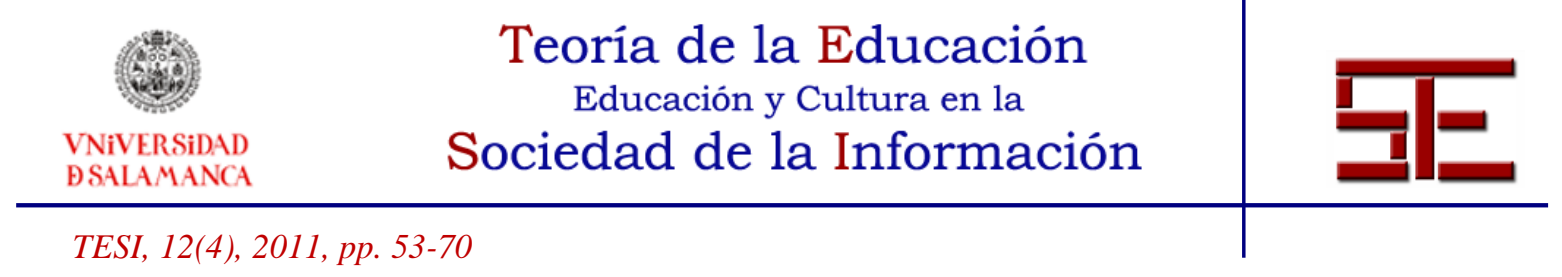

Alexander, B. (2006). Web 2.0: A new wave of innovation for teaching and learning? EDUCAUSE Review, 41 (2), 32-44.

Atwell, G. (2008). The Personal Learning Environments - the future of e-learning? eLearning Papers, 2, (1).

Ariel Villagra, H. (2005). La utilización de una guía multimedia como recurso didáctico en la formación de los maestros de educación física. En M. Casanovas, M. C. Jové y A. Tolmos (Eds.). Las TIC en la formación del profesorado. La perspectiva de las didácticas específicas (pp. 55-65). Universidad de Lleida.

Comisión Europea (2007). Competencias clave para el aprendizaje permanente. Un Marco de Referencia Europeo. Luxemburgo: Oficina de Publicaciones Oficiales de las Comunidades Europeas.

Contreras, F. (2004). Weblog en Educación. En S. Hernández Requena (2008). El modelo constructivista con las nuevas tecnologías: aplicado en el proceso de aprendizaje. Revista de Universidad y Sociedad del Conocimiento, 2 (5), 26-35. Extraído el 10, octubre, 2011 en http://www.uoc.edu/rusc/5/2/dt/esp/hernandez.pdf.

De Haro, J. J. (2010a). Redes sociales para la educación. Madrid: Anaya Multimedia.

- De Haro, J. J. (2010b). Blog sobre calidad e innovación en educación secundaria. Mensaje posteado (02/02/2010). Extraído el 15, febrero, 2011 en http://jjdeharo.blogspot.com/.

Echazarreta, C., Prados, F., Poch, J. \& Soler, J. (2009). La competencia "El trabajo colaborativo": una oportunidad para incorporar las TIC en la didáctica universitaria. Descripción de la experiencia con la plataforma ACME (UdG). UOC Papers: revista sobre la Sociedad del Conocimiento, 8. Extraído el 17, octubre, 2011 de http://bit.ly/urXavI.

Espuny, C., Gisbert, M., González, J. \& Cordura, J. (2010). Los seminarios TAC. Un reto de formación para asegurar la dinamización de las TAC en las escuelas. EDUTEC, Revista Electrónica de Tecnología Educativa, 34. Extraído el 26, mayo, 2011 de http://bit.ly/tOEFuc.

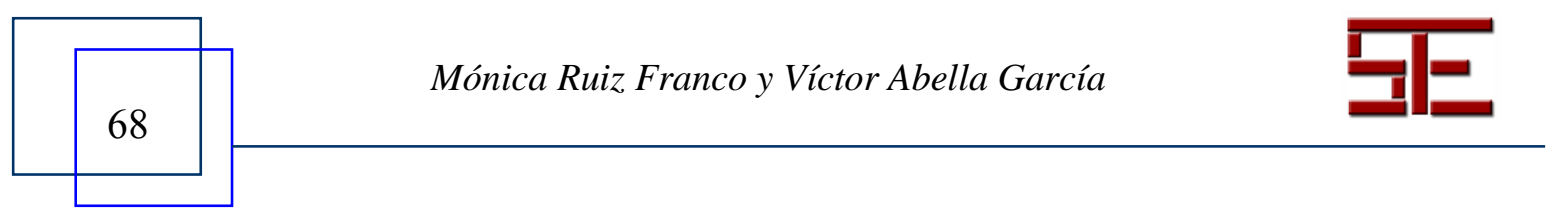




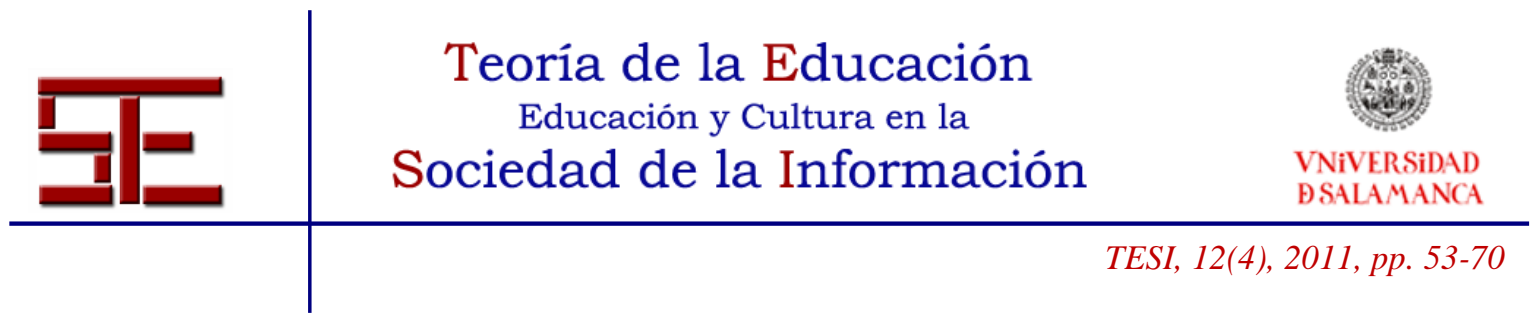

Ferdig, R. (2007). Examining social software in teacher education. Journal of Technology and Teacher Education, 15 (1), 5-10.

Gutiérrez Martín, A. (2009). Formación del Profesorado y Tecnologías de la Información y la Comunicación. Renovación y convergencia para la Educación 2.0 en el (Ciber)Espacio Europeo de Educación Superior. Revista Electrónica de Teoría de la Educación: Educación y Cultura en la Sociedad de la Información, 1 (10), 93-111. Extraído el 25, Mayo, de http://bit.ly/t3wLJZ.

Hernández Requena, S. (2008). El modelo constructivista con las nuevas tecnologías: aplicado en el proceso de aprendizaje. Revista de Universidad y Sociedad del Conocimiento, 2 (5), 26-35. Extraído el 10, octubre, 2011 en http://www.uoc.edu/rusc/5/2/dt/esp/hernandez.pdf.

López Meneses, E. (2009). Innovar con blog en las aulas universitarias. Revista DIM: Didáctica, Innovación y Multimedia, 14. Extraído el 26, mayo, 2011 de http://bit.ly/uWwRli.

Lozano, J. M. (2008). La Web 2.0. Avances en Supervisión Educativa. Revista de la Asociación de Inspectores de Educación en España, 8.

Lozano, R. (2011). Las TIC/TAC: de las tecnologías de la información y comunicación a las tecnologías del aprendizaje y del conocimiento. Mensaje posteado (21/01/2011). Extraído el 12, octubre, 2011 de http://bit.ly/ijF8mQ.

Maloney, E. J. (2007). What Web 2.0 can teach us about learning. Chronicle of Higher Education, 53 (18), B26.

Rodríguez Izquierdo, R. Ma . (2010). El impacto de las TIC en la transformación de la enseñanza universitaria: repensar los modelos de enseñanza y aprendizaje. Revista Electrónica de Teoría de la Educación: Educación y Cultura en la Sociedad de la Información, 11 (3), 32-68. Extraído el 25 Mayo, 2011, de http://bit.ly/vShHA1.

Sancho Gil, J. Ma . (2008). De TIC a TAC, el difícil tránsito de una vocal. Investigación en la escuela, 64, 19-33. Extraído el 15, abril, 2011, de http://bit.ly/w0oahS.

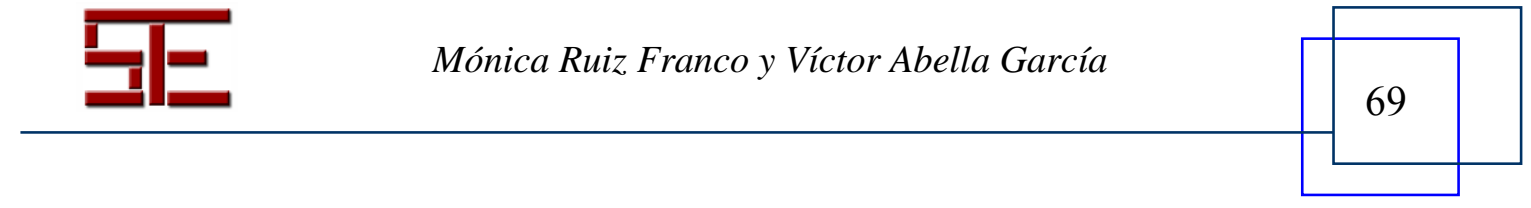


Vivancos, J. (2011a). Aproximación a la competencia digital docente. Mensaje posteado (15/06/2011). Extraído el 12, octubre, 2011 de http://ticotac.blogspot.com/.

- (2011b). Enseñanzas de las Ciencias con apoyo TAC. Mensaje posteado (20/02/2011). Extraído el 12, octubre, 2011de http://ticotac.blogspot.com/.

Para citar el presente artículo puede utilizar la siguiente referencia:

Ruiz Franco, M. y Abella García, V. (2011). Creación de un blog educativo como herramienta TIC e instrumento TAC en el ámbito universitario. Revista Teoría de la Educación: Educación y Cultura en la Sociedad de la Información. 12(4), 53-70 [Fecha de consulta: $\mathrm{dd} / \mathrm{mm} /$ aaaa $]$.

http://campus.usal.es/ revistas_trabajo/index.php/revistatesi/article/view/8526/8612 